\title{
Genetically enhanced
} growth causes increased mortality in hypoxic environments

\author{
L. Sundt-Hansen ${ }^{1, *}$, L. F. Sundström ${ }^{2}$, \\ S. Einum ${ }^{1,3}, K_{\text {. Hindar }}{ }^{1}$, I. A. Fleming ${ }^{4}$ \\ and R. H. Devlin ${ }^{2}$
${ }^{1}$ Norwegian Institute for Nature Research, Tungasletta 2, 7485 Trondheim, Norway
${ }^{2} \mathrm{DFO} / \mathrm{UBC}$ Centre for Aquaculture and Environmental Research, West Vancouver, British Columbia, Canada V6T $1 Z 4$
${ }^{3}$ Department of Biology, Realfagbygget, Norwegian University of Science and Technology, 7491 Trondheim, Norway
${ }^{4}$ Ocean Sciences Centre, Memorial University, St fohns, Newfoundland A1C 5S7, PO Box 4200, Canada
*Author for correspondence (line.sundt-hansen@nina.no).

Rapid growth and development are associated with several fitness-related benefits. Yet, organisms usually grow more slowly than their physiological maximum, suggesting that rapid growth may carry costs. Here we use coho salmon (Oncorhynchus kisutch) eggs of wild and transgenic genotypes to test whether rapid growth causes reduced tolerance to low levels of oxygen (hypoxia). Eggs were exposed to four different durations of hypoxia, and survival and growth were recorded until the end of the larval stage. Survival rates decreased with increasing duration of hypoxia, but this decrease was most pronounced for the transgenic group. Larval mass was also negatively affected by hypoxia; however, transgenic genotypes were significantly larger than wild genotypes at the end of the larval stage. Oxygen can be a limiting factor for survival and development in a wide range of organisms, particularly during the egg stage. Thus, the reduced ability of fast-growing genotypes to cope with low oxygen levels identified in the present study may represent a general constraint on evolution of rapid growth across taxa.

Keywords: hypoxia; eggs; mortality; salmon; transgenic

\section{INTRODUCTION}

Rapid growth is associated with several fitness-related benefits, such as increased competitive ability, reduced time spent in vulnerable life stages and thus higher chances of surviving to reproduction (Arendt 1997). Yet, organisms rarely grow at their physiological maximum, as indicated by positive responses to insertion of growth hormone (GH; Johnsson \& Björnsson 1994) and GH genes (Devlin et al. 1994), and compensatory growth (Metcalfe \& Monaghan 2001). This suggests that selection for rapid growth is counteracted by costs which prevent evolution of maximum growth.

One potential cost that has received little attention previously is the effect of rapid growth on tolerance to low oxygen (hypoxic) conditions. Such costs may be particularly important in aquatic environments, where the supply of dissolved oxygen is in general lower and more variable than in terrestrial systems, commonly causing mortality and shaping community composition (Keister et al. 2000). Here, we use coho salmon (Oncorhynchus kisutch) eggs to study responses to hypoxia. The salmon egg represents a suitable model organism for this question because it, in common with eggs of many aquatic organisms, lacks the possibility to actively evade hypoxic conditions and commonly experiences hypoxia-induced mortality (Wannamaker \& Rice 2000). We controlled for genetically correlated traits (e.g. Lande \& Arnold 1983) and maternal effects (Einum et al. 2002) by producing half-sib groups fertilized by GH-transgenic and wild-type males originating from the same stock. Any difference in performance between the transgenic and wild half-sib groups would be a result of a single gene insertion that enhances growth by overexpressing GH (Devlin et al. 2001). We then compared the performance of the two types of crosses under hypoxic conditions to test the hypothesis that low oxygen levels may constrain the evolution of growth rates.

\section{MATERIAL AND METHODS}

The experiment was conducted at the DFO/UBC Centre for Aquaculture and Environmental Research (CAER), West Vancouver. Fast-growing genotypes of coho salmon were initially produced by microinjecting the OnMTGH1 growth hormone gene construct into eggs from wild parents from the Chehalis River in southwestern British Columbia (Devlin et al. 1994, 2004). Wild coho males and females were obtained from the Chehalis River, southwestern British Columbia, in February 2005. Crosses were made 2 February, using 25 wild coho females (mean body weight \pm s.d.: $3186 \pm 710 \mathrm{~g}$ ), with the eggs from each female split into two batches. One batch from each female was fertilized by one of six males homozygous for the transgene (strain M77, only six mature males from the broodstock) and the other by one of six wild coho males. Eggs were incubated in fresh well water at $10 \pm 1^{\circ} \mathrm{C}$.

\section{(a) Hypoxia treatment}

Eggs were subjected to hypoxia at the eyed stage (34 days postfertilization) when oxygen is critical for embryo survival and development (Alderdice et al. 1958). Four samples of 75 randomly selected eggs from each of the 50 family groups ( 25 transgenic and 25 wild) were placed in separate containers. The four samples from each family were exposed to hypoxia for one of four different durations $(0,12,36$ and $72 \mathrm{~h})$. The mean oxygen concentration during the treatment was $2.37 \mathrm{mg}^{-1}$ (s.d.: 0.57 ), which is similar to the hypoxia treatment used by Einum et al. (2002). The temperature during the experiment was $10 \pm 1^{\circ} \mathrm{C}$. Oxygen was removed from the water using a standard oxygen-stripping column with flow-through nitrogen to displace oxygen (for details, see Einum et al. 2002). A sample of 20 eggs from each family group were weighed individually (wet weight) just prior to start of hypoxia exposure (33 days post-fertilization).

Dead offspring were recorded and removed on $21,24,29$ March, and 4 and 11 April. Hatching occurred just prior to the first removal of dead offspring. The experiment was terminated on 11 April (end of the larval stage), when 10 randomly selected larvae from each family group and treatment were weighed. Overall survival rates were measured from the start of manipulation to experiment termination.

\section{(b) Statistics}

Survival rates within family groups and treatments were arcsin square root transformed. ANCOVAs were used to test for the effect of hypoxia on survival rate and larval body mass with treatment and type (transgenic versus wild) being entered as fixed factors, and egg mass as a covariate (cf. Einum et al. 2002). All non-significant interaction terms were excluded prior to the final ANCOVAs. Paired $t$-tests served as post hoc test for the ANCOVAs. 


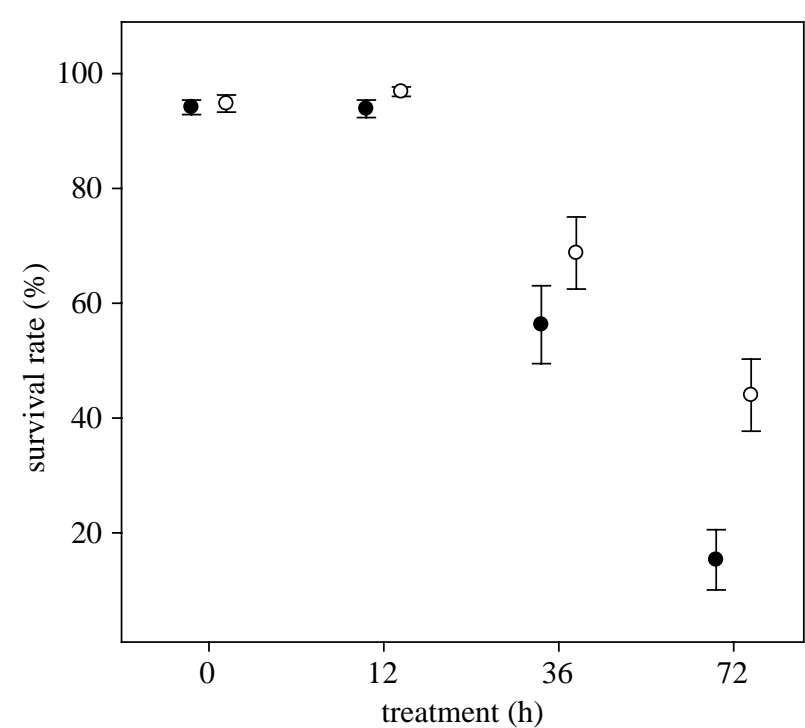

Figure 1. Survival rates per family of transgenic (filled circle) and wild (open circle) coho salmon larvae after hypoxia treatment $(0,12,36$ and $72 \mathrm{~h})$. Error bars represent one standard error.

Table 1. ANCOVAs testing for the effects of type (transgenic versus wild), oxygen treatment and egg mass on survival rate and body mass of coho salmon larvae.

\begin{tabular}{lllrlll}
\hline & $\begin{array}{l}\text { effect } \\
\text { effect }\end{array}$ & $\begin{array}{l}\text { error } \\
\text { d.f. }\end{array}$ & \multicolumn{1}{l}{$F$} & \multicolumn{1}{c}{$p$} & $\beta$ \\
\hline survival rate & & & & & \\
type & 1 & 190 & 16.49 & $<0.0001$ & \\
treatment & 3 & 190 & 103.46 & $<0.0001$ & \\
type $\times$ treatment & 3 & 190 & 4.55 & 0.004 & \\
egg mass & 1 & 190 & 0.32 & 0.572 & -0.001 \\
larval mass & & & & & \\
type & 1 & 171 & 42.29 & $<0.0001$ & \\
treatment & 3 & 171 & 7.53 & $<0.0001$ & \\
egg mass & 1 & 171 & 536.57 & $<0.0001$ & 0.001 \\
\hline
\end{tabular}

\section{RESULTS}

\section{(a) Survival}

Exposure to hypoxia (treatment) had a significant overall negative effect on final survival (figure 1; table 1) and there was also a significant effect of genotype (wild versus transgenic; figure 1; table 1). However, the interaction term between genotype and treatment was significant, indicating that the two genotypes responded differentially to the hypoxia treatment (table 1). In the $0 \mathrm{~h}$ treatment, mean survival rate was high for both the transgenic (mean \pm s.d.: $94 \pm 6 \%$ ) and the wild $(95 \pm 7 \%$ ) groups, and these groups did not differ significantly (figure 1; table 2). Survival rates decreased for both groups with increasing duration of hypoxia. This decrease was most pronounced for the transgenic group, which showed significantly lower survival than the wild group in two of the three hypoxia treatments (12 and $72 \mathrm{~h}$ treatment; figure 1; table 2). Egg mass, however, did not have a significant effect on survival rate (table 1 ).

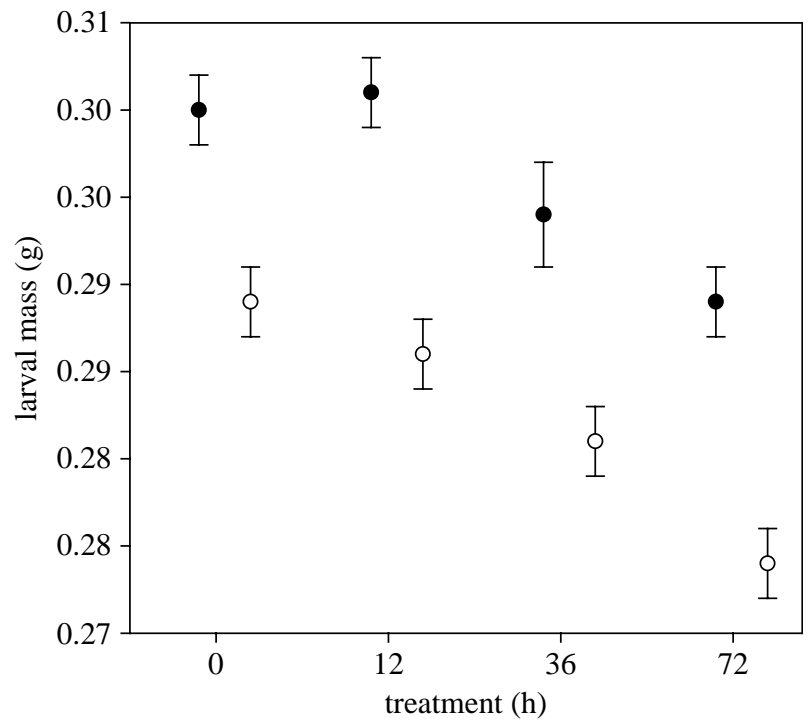

Figure 2. Average larval mass of transgenic (filled circle) and wild (open circle) coho salmon in the different treatments. Error bars represent one standard error.

Table 2. Paired samples $t$-tests comparing average body mass and survival rate of transgenic and wild coho salmon larvae in the different hypoxia treatments. (In the $0 \mathrm{~h}$ treatment, d.f. was 23 due to loss of one family group. For analysis of larval mass, some family groups could not be sampled due to high mortality.)

\begin{tabular}{llll}
\hline treatment & $t$ & d.f. & $p$ \\
\hline survival rate & & & \\
$0 \mathrm{~h}$ & 0.37 & 23 & 0.712 \\
$12 \mathrm{~h}$ & 2.96 & 24 & 0.007 \\
$36 \mathrm{~h}$ & 1.33 & 24 & 0.196 \\
$72 \mathrm{~h}$ & 3.98 & 24 & 0.001 \\
larval mass & & & \\
$0 \mathrm{~h}$ & 5.07 & 23 & $<0.0001$ \\
$12 \mathrm{~h}$ & 9.79 & 24 & $<0.0001$ \\
$36 \mathrm{~h}$ & 4.01 & 23 & 0.001 \\
$72 \mathrm{~h}$ & 5.35 & 8 & 0.001 \\
\hline
\end{tabular}

\section{(b) Body mass}

Larval mass was significantly affected by both genotype and the hypoxia treatment (table 1), with a decrease in mass as exposure time to hypoxic conditions increased (figure 2). Transgenic larvae were significantly larger than wild larvae in all treatments (table 2).

\section{DISCUSSION}

Transgenic salmon were used as a model for testing whether rapid growth causes reduced tolerance to hypoxia. Prolonged hypoxia treatment reduced survival of both transgenic and wild offspring; however, the impact on survival rate was stronger in the transgenic groups. The lower tolerance to hypoxic conditions observed in our transgenic genotypes may be caused by higher metabolic requirements. GH-transgenic fish have elevated routine metabolic rates of up to 1.7 times that of wild genotypes at later developmental stages (Stevens et al. 1998; Leggatt et al. 2003). Such differences in metabolic rate may be due to differences in basal metabolic rate and/or 
differences in behavioural activity. It is not known whether the basal metabolism differs between transgenic and wild coho during the egg stage, but if so it would also cause a higher oxygen requirement. Alternatively, hypoxia effects on particular biochemical pathways or morphological structures may be more critical under the accelerated development of transgenic larvae. A difference in developmental stage between the transgenic and wild genotypes during exposure could in theory also contribute to a difference in hypoxia tolerance. Eggs increase their oxygen demand as they develop, which makes them more sensitive to low oxygen levels as their development proceeds towards hatching (Alderdice et al. 1958). However, since our transgenic eggs were hemizygous, and the treatment was applied approximately two weeks prior to hatching, any difference in development at that stage should, on average, be less than the observed 2.5 day advance in hatching date of homozygous transgenic eggs (Devlin et al. 2004) and less than the duration of the $72 \mathrm{~h}$ treatment in which the most pronounced difference in survival was observed.

Einum et al. (2002) showed that a large egg mass was beneficial in terms of survival under low oxygen levels. In the present study, no effect of egg mass on survival was observed. A reason for this might be that we did not attain eggs varying in size from the same female (cf. Einum et al. 2002) and hence any correlation between egg mass and other egg features (maternal and genetic) could not be controlled for.

Oxygen availability in freshwater ecosystems is often low relative to that in air and aquatic eggs must be able to cope with the stress of low oxygen. Symptoms of this include reduced rates of metabolism, protein synthesis and growth (Nikinmaa \& Rees 2005). However, oxygen limitation may be important even in terrestrial eggs (e.g. lizards, Andrews 2002; chickens, Sharma et al. 2006) and high oxygen requirements in warm environments may constrain evolution of viviparity in reptiles (Andrews 2002). Thus, the reduced ability of fast-growing genotypes to cope with low oxygen levels in the present study may represent a general constraint on evolution of rapid growth across taxa.

The reduced larval body mass as a result of hypoxia exposure is in accordance with studies across a range of taxa (e.g. fishes, Alderdice et al. 1958; frogs and salamanders, Mills \& Barnhart 1999; lizards, Andrews 2002; chickens, Sharma et al. 2006). Although final body mass was inhibited by hypoxia, transgenic larvae were significantly larger than their wild half-siblings in all treatments. This may imply a more efficient conversion of stored yolk sac energy reserves to body mass in transgenic eggs due to overexpression of GH (Devlin et al. 1995).

Our results also provide insight into the ecological effects of escaped transgenic fish and their potential viability in a natural environment. Surviving transgenic offspring were larger than wild offspring, and this combined with their advanced timing of emergence (Devlin et al. 2004) may provide a competitive advantage in some situations (Einum \& Fleming 2000). However, with high abundance of predators and low food availability emerging transgenic fry show poorer survival than wild coho fry (Sundström et al. 2005). Knowledge of such genotype $\times$ environment interactions is crucial for predicting the risk posed by escaped transgenic organisms. Our experiment has identified an additional interaction, showing that the relative viability of the two genotypes is strongly dependent on oxygen conditions, and that selection against transgenic offspring may occur as early as during the embryo stage.

To our knowledge, this is the first study to identify a physiological cost of rapid growth at the embryo stage in aquatic environments. The demonstrated trade-off between rapid growth and survival in hypoxic environments may represent a major selective force shaping evolution of growth rates, at least in egg-laying species, which may contribute to explain the submaximal growth observed in juveniles across a range of taxa (Arendt 1997; Metcalfe \& Monaghan 2001).

We thank Carlo Biagi, Nicole Hofs and all the rest of Dr R.H. Devlins group at CAER for their technical assistance, and two anonymous referees for their comments. The work was supported by the FUGE program of the Research Council of Norway and the Canadian Regulatory System for Biotechnology.

Alderdice, D. F., Wickett, W. P. \& Brett, J. R. 1958 Some effects of temporary exposure to low dissolved oxygen levels on pacific salmon eggs. F. Fish. Res. Board Can. 15, 229-249.

Andrews, R. M. 2002 Low oxygen: a constraint on the evolution of viviparity in reptiles. Physiol. Biochem. Zool. 75, 145-154. (doi:10.1086/339388)

Arendt, J. D. 1997 Adaptive intrinsic growth rates: integration across taxa. Q. Rev. Biol. 72, 149-177. (doi:10. 1086/419764)

Devlin, R. H., Yesaki, T. Y., Biagi, C. A., Donaldson, E. M., Swanson, P. \& Chan, W. K. 1994 Extraordinary salmon growth. Nature 371, 209-210. (doi:10.1038/ 371209a0)

Devlin, R. H., Yesaki, T. Y., Donaldson, E. M. \& Hew, C. L. 1995 Transmission and phenotypic effects of an antifreeze $\mathrm{GH}$ gene construct in coho salmon (Oncorhynchus kisutch). Aquaculture 137, 161-169. (doi:10.1016/0044-8486(95)01090-4)

Devlin, R. H., Biagi, C. A., Yesaki, T. Y., Smailus, D. E. \& Byatt, J. C. 2001 Growth of domesticated transgenic fish - a growth-hormone transgene boosts the size of wild but not domesticated trout. Nature 409, 781-782. (doi:10.1038/35057314)

Devlin, R. H., Biagi, C. A. \& Yesaki, T. Y. 2004 Growth, viability and genetic characteristics of $\mathrm{GH}$ transgenic coho salmon strains. Aquaculture 236, 607-632. (doi:10. 1016/j.aquaculture.2004.02.026)

Einum, S. \& Fleming, I. A. 2000 Selection against late emergence and small offspring in Atlantic salmon (Salmo salar). Evolution 54, 628-639. (doi:10.1554/0014-3820 (2000)054[0628:SALEAS]2.0.CO;2)

Einum, S., Hendry, A. P. \& Fleming, I. A. 2002 Egg-size evolution in aquatic environments: does oxygen availability constrain size? Proc. R. Soc. B 269, 2325-2330. (doi:10.1098/rspb.2002.2150)

Johnsson, J. I. \& Björnsson, B. T. 1994 Growth hormone increases growth rate, appetite and dominance in juvenile rainbow trout (Oncorhynchus mykiss). Anim. Behav. 48, 177-186. (doi:10.1006/anbe.1994.1224) 
Keister, J. E., Houde, E. D. \& Breitburg, D. L. 2000 Effects of bottom-layer hypoxia on abundances and depth distributions of organisms in Patuxent River, Chesapeake Bay. Mar. Ecol. Prog. Ser. 205, 43-59.

Lande, R. \& Arnold, S. J. 1983 The measurement of selection on correlated characters. Evolution 37, 1210-1226. (doi:10.2307/2408842)

Leggatt, R. A., Devlin, R. H., Farrell, A. P. \& Randall, D. J. 2003 Oxygen uptake of growth hormone transgenic coho salmon during starvation and feeding. F. Fish Biol. 62, 1053-1066. (doi:10.1046/j.1095-8649. 2003.00096.x)

Metcalfe, N. B. \& Monaghan, P. 2001 Compensation for a bad start: grow now, pay later? Trends Ecol. Evol. 16, 254-260. (doi:10.1016/S0169-5347(01)02124-3)

Mills, N. E. \& Barnhart, M. C. 1999 Effects of hypoxia on embryonic development in two Ambystoma and two Rana species. Physiol. Biochem. Zool. 72, 179-188. (doi:10.1086/316657)
Nikinmaa, M. \& Rees, B. B. 2005 Oxygen-dependent gene expression in fishes. Am. F. Physiol. 288, R1079-R1090.

Sharma, S. K., Lucitti, J. L., Nordman, C., Tinney, J. P., Tobita, K. \& Keller, B. B. 2006 Impact of hypoxia on early chick embryo growth and cardiovascular function. Pediatr. Res. 59, 116-120. (doi:10.1203/01.pdr.0000191 579.63339.90)

Stevens, E. D., Sutterlin, A. \& Cook, T. 1998 Respiratory metabolism and swimming performance in growth hormone transgenic Atlantic salmon. Can. F. Fish. Aquat. Sci. 55, 2028-2035. (doi:10.1139/cifas-55-9-2028)

Sundström, L. F., Lõhmus, M. \& Devlin, R. H. 2005 Selection on increased intrinsic growth rates in coho salmon Oncorhynchus kisutch. Evolution 59, 1560-1569. (doi:10.1554/04-701)

Wannamaker, C. M. \& Rice, J. A. 2000 Effects of hypoxia on movements and behavior of selected estuarine organisms from the southeastern United States. F. Exp. Mar. Biol. Ecol. 249, 145-163. (doi:10.1016/S0022-0981(00)00160-X) 